\title{
The dynamical background of polar mesosphere winter echoes from simultaneous EISCAT and ESRAD observations
}

\author{
E. Belova $^{1}$, S. Kirkwood ${ }^{1}$, J. Ekeberg ${ }^{1}$, A. Osepian ${ }^{2}$, I. Häggström ${ }^{3}$, H. Nilsson ${ }^{1}$, and M. Rietveld ${ }^{4}$ \\ ${ }^{1}$ Swedish Institute of Space Physics, Box 812, 98128 Kiruna, Sweden \\ ${ }^{2}$ Polar Geophysical Institute, Halturina 15, Murmansk, Russia \\ ${ }^{3}$ EISCAT Scientific Association, Box 164, 98123 Kiruna, Sweden \\ ${ }^{4}$ EISCAT Scientific Association, Ramfjordmoen, N-9027 Ramfjordbotn, Norway
}

Received: 10 December 2004 - Revised: 9 March 2005 - Accepted: 22 March 2005 - Published: 3 June 2005

\begin{abstract}
On 30 October 2004 during a strong solar proton event, layers of enhanced backscatter from altitudes between 55 and $75 \mathrm{~km}$ have been observed by both ESRAD $(52 \mathrm{MHz})$ and the EISCAT VHF $(224 \mathrm{MHz})$ radars. These echoes have earlier been termed Polar Mesosphere Winter Echoes, PMWE. After considering the morphology of the layers and their relation to observed atmospheric waves, we conclude that the radars have likely seen the same phenomenon even though the radars' scattering volumes are located about $220 \mathrm{~km}$ apart and that the most long-lasting layer is likely associated with wind-shear in an inertio-gravity wave. An ion-chemistry model is used to determine parameters necessary to relate wind-shear induced turbulent energy dissipation rates to radar backscatter. The model is verified by comparison with electron density profiles measured by the EISCAT VHF radar. Observed radar signal strengths are found to be 2-3 orders of magnitude stronger than the maximum which can be expected from neutral turbulence alone, assuming that previously published results relating radar signal scatter to turbulence parameters, and turbulence parameters to wind shear, are correct. The possibility remains that some additional or alternative mechanism may be involved in producing PMWE, such as layers of charged dust/smoke particles or large cluster ions.
\end{abstract}

Keywords. Radio science (Ionospheric physics) - Meterology and atmospheric dynamics (Middle atmosphere dynamics) - Atmospheric composition and structure (Middle atmosphere-composition and chemistry)

\section{Introduction}

Polar Mesosphere Summer Echoes (PMSE), which are very strong radar returns from $80-90 \mathrm{~km}$ altitude, seen in the summertime at polar latitudes, have been studied intensively since their discovery more than 20 years ago (for reviews

Correspondence to: S. Kirkwood

(sheila.kirkwood@irf.se) see Cho and Röttger, 1997 and Rapp and Lübken, 2004). At PMSE heights, radar backscatter is caused by electron density perturbations with scale-sizes corresponding to the radar Bragg wavelength (which is half the radar wavelength). PMSE have been detected with radars operating over a wide frequency range, from a few $\mathrm{MHz}$ up to almost $1 \mathrm{GHz}$, corresponding to Bragg wavelengths from a few meters to several centimetres. Neutral turbulence is common at these heights as a result of breaking gravity waves, and is expected to result in small-scale electron density fluctuations. However, it has been found that such neutral turbulence on its own cannot account for observed PMSE strengths, particularly at short wavelengths. PMSE have been shown to be associated with aerosol ice particles (Havnes et al., 2001; Hervig et al., 2001). Such particles are formed close to the polar mesopause in summertime due to the very low temperatures occurring there (Lübken, 1997). Aerosol particles very rapidly become negatively charged (Lie-Svednsen et al., 2003) by electron attachment and this reduces electron diffusivity. The reduced diffusivity leads to an increase in the Schmidt number (ratio of kinematic viscosity to electron diffusivity) which allows turbulent fluctuations to persist in the electron gas at shorter length-scales than would otherwise be possible (Cho et al., 1992).

In the last 4 years many observations of enhanced echoes from the mesosphere in the wintertime have been reported from ESRAD MST $(52 \mathrm{MHz}$ ) radar (Kirkwood et al., 2002a,b; Kirkwood et al., 2003; Stebel et al., 2004). These have been termed Polar Mesosphere Winter Echoes (PMWE) in analogy to PMSE. PMWE are generally weaker than PMSE but they are seen over a wider range of altitudes, from $50-80 \mathrm{~km}$. VHF radar echoes from the winter mesosphere were first reported from the Poker Flat radar in Alaska by Balsley et al. (1983) and it was proposed that they could be caused by turbulence produced by breaking gravity waves. ESRAD observations have allowed more details of PMWE morphology to be determined. PMWE are seen only when ionisation at mesospheric heights is enhanced due to solar proton events or to high-energy electron precipitation from 
the magnetosphere, and when the ratio of free electrons to negative ions is expected to be reasonably large (i.e. only during daylight below $70 \mathrm{~km}$ altitude). In considering whether PMWE can be explained by neutral turbulence alone, it is necessary to take into account the fact that when significant numbers of negative ions are present, as they generally are below $70-75 \mathrm{~km}$ altitude, electron diffusivity is substantially enhanced (Hill, 1978). This reduces the radar signal strength which can be expected to result from turbulence alone. Stebel et al. (2004) have shown that the radar reflectivities for winter conditions from turbulence theory (assuming maximum likely turbulence levels) are 1-2 orders of magnitude less than those measured in PMWE by the ESRAD radar. Kirkwood et al. (2003) have further shown that wind, density and temperature profiles from meteorological rockets traversing PMWE heights do not see (at those heights) the kind of conditions which are expected to lead to turbulence. Stebel et al. (2004) also showed that anomalous lidar backscatter from the same height as PMWE could reasonably be interpreted in terms of an aerosol-particle layer. This leads to the suggestion that layers of charged aerosol particles could be associated with PMWE in a similar way to PMSE. However, in the case of PMWE there is no clear candidate for such aerosol-particles. The winter mesosphere is too warm for ice-particles to form and the other expected source of particles, meteor ablation (Hunten et al., 1981), is not expected to give particles of sufficient size or number to be detectable by, for example, lidar.

Collis et al. (1992) were the first to report enhanced backscatter from mesospheric heights during a wintertime solar-proton event from the EISCAT VHF radar (224 MHz). Collis et al. (1992) assumed that the backscatter was due to turbulence and used the backscatter strength to calculate turbulent energy dissipation rates. The rates they derived were much higher than were later found to be usual by a large number of sounding rocket measurements (Lübken et al., 1993). Collis et al. (1992) also did not take into account the likely presence of negative ions - if they had done this, their turbulent energy estimates would have been even higher. Kirkwood et al. (2002b) presented the first observations of PMWE detected simultaneously by both the ESRAD and EISCAT VHF radars, during a solar proton event on 4 November 1997. Both radars saw signals from the same height, however, the EISCAT radar signal was detectable during only a few minutes, a much shorter time than the ESRAD signal.

Here we present observations of PMWE with both ESRAD and the EISCAT VHF radar during the major solar proton event on 30 October 2003. We discuss the morphology of the layers and their relation to the background wind field. We compare electron densities measured with the EISCAT radar during this period to those modelled using an ion-chemistry model of the lower ionosphere. Finally, with the help of the model, we estimate the maximum radar reflectivity which might be expected due to turbulence alone and compare this with measurements by both radars.
The enhanced electron densities produced in the mesosphere as a result of the solar proton event, with only slow variations over a period of many hours, are necessary to make this region "visible" to the radars. No matter what underlying structure may be present in the neutral atmosphere at mesospheric heights, it will not have caused measureable scatter of the VHF radio waves used by the radars unless it is coupled to structures in electron density. This means that the majority of PMWE observations reported from the relatively low-sensitivity ESRAD radar have been made during solar proton events, which are the occasions when the electron density at the relevant heights is most enhanced. However, PMWE have been observed outside solar proton events, both by more sensitive MST radars previously operational at Poker Flat, Alaska (Balsley et al., 1983) and Andøya, Norway (Czechowsky et al., 1989), and on a few occasions by ESRAD as well (e.g. Kirkwood et al., 2003). On those occasions, high-energy electron precipitation from within the magnetosphere was the most likely cause of enhanced electron densities. Further, it should be noted that the ESRAD radar has also operated during a major solar proton event during the summer of July, without any detectable scattering layers other than those normally seen throughout the summer months between 75 and $95 \mathrm{~km}$ altitudes (Barabash et al., 2004). These considerations lead us to believe that the primary cause of PMWE lies in the background neutral atmosphere, and not in the nature of the agent causing the enhanced electron density. So in this paper we focus on the possible role of the neutral background atmosphere.

\section{Observations}

Strong solar proton events (SPE) produced by powerful solar flares took place on 28-30 October 2003. Energetic solar protons arriving at high latitudes caused substantial ionisation at mesospheric heights (50-90 km altitude). The ESRAD MST radar located at Esrange, Sweden, $67.9^{\circ} \mathrm{N}$, $21.1^{\circ} \mathrm{E}$ (Chilson et al., 1999) was running two experimental modes - one with 600-m height resolution (8-bit complementary code) and one with 300-m height resolution (16-bit complementary code). The results in this paper are based on the 600-m observations which were made on alternate minutes, with the radar beam directed vertically. On 29 October at 08:00 UT the EISCAT VHF radar located near Troms $\varnothing$, Norway, at $69.6^{\circ} \mathrm{N}, 19.2^{\circ} \mathrm{E}$, started to run the "arc_dlayer" experiment, specially designed for the lower ionosphere at ranges from $60 \mathrm{~km}$ to $126.6 \mathrm{~km}$, with a range resolution of $300 \mathrm{~m}$. In order to measure at heights below $60 \mathrm{~km}$ the radar beam was tilted towards the north and most daytime observations were made at $60^{\circ}$ elevation. (For further technical details of the EISCAT radar and the particular measurement mode, see http://www.eiscat.com.) PMWE were seen by both EISCAT and ESRAD on both 29 and 30 October, however, the EISCAT PMWE were short-lived on 29 October, so here we focus on the observations on 30 October. 

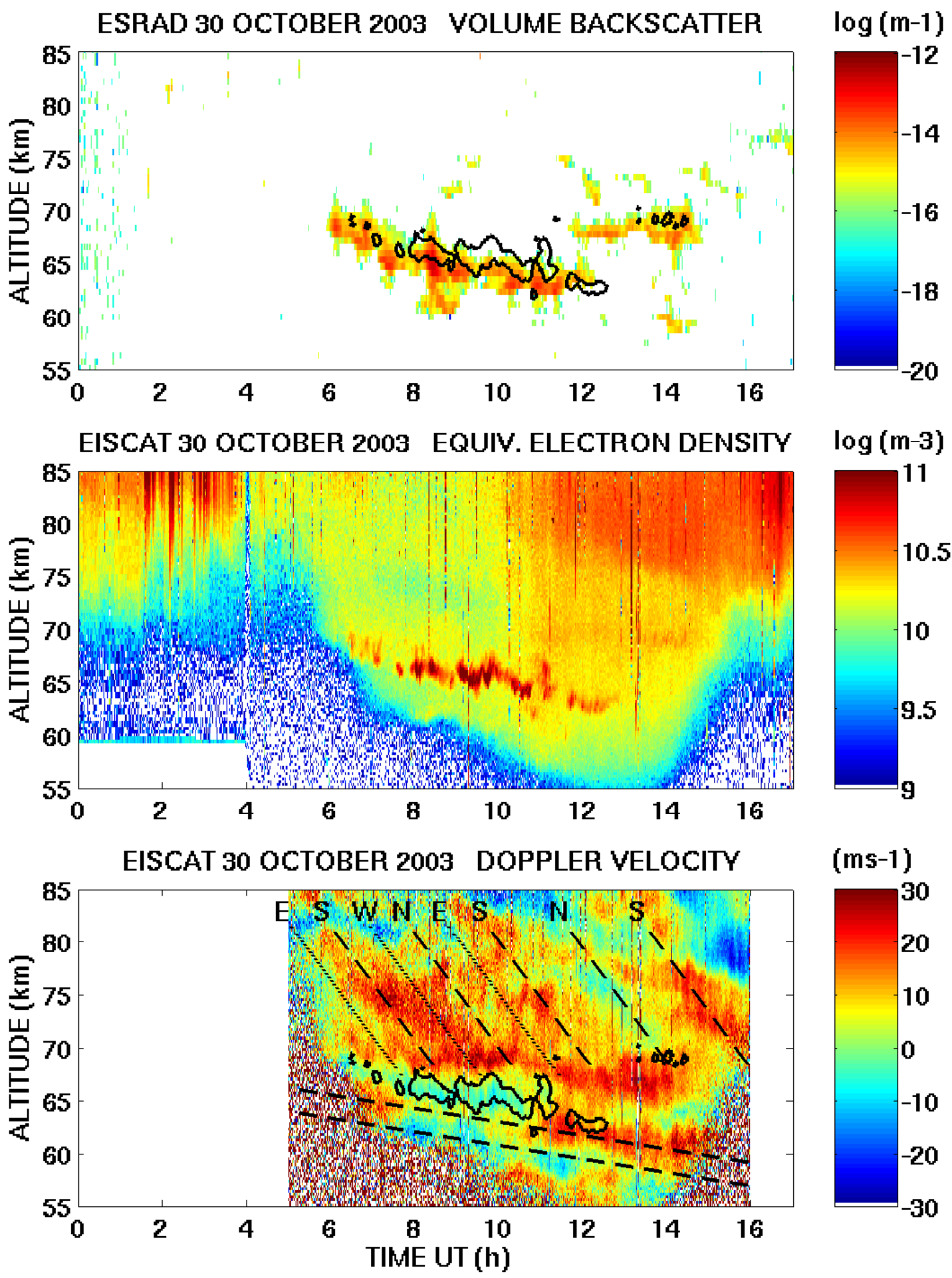

Fig. 1. ESRAD and EISCAT observations for 30 October 2003. Upper panel: volume backscatter from ESRAD; middle panel: equivalent electron density from the EISCAT VHF rada; lowermost panel: Doppler velocity of radar scatterers along the direction of the radar beam (inclined at $60^{\circ}$ elevation towards the north, (positive towards the radar)). Superimposed contour lines on the uppermost and lowermost panels indicate the height/time location of the PMWE seen by EISCAT. In the lowermost panel, the dashed lines at low altitudes indicate the maxima and minima in the wave velocity field used to estimate vertical wavelength and apparent period of the main inertio-gravity wave. The dashed and dotted lines at higher altitudes indicate the inferred positions of maximum winds in a second inertio-gravity wave (see text for further details). 
The upper two panels in Fig. 1 show range-corrected backscattered power from the ESRAD and EISCAT radar measurements for 30 October. The ESRAD observations are plotted in units of volume scatter, whereas for EISCAT power is plotted in units of equivalent electron density, which includes both the true electron density and additional scatter due to PMWE. The normal electron density is enhanced due to energetic proton (and electron) precipitation. This electron density enhancement covers all heights, varying smoothly with height at any time. There is a strong variation of the electron density below $80 \mathrm{~km}$ between night and day. For example, the atmosphere at $70 \mathrm{~km}$ height is sunlit from about 06:00 UT until about 14:00 UT, with rather high electron densities. When the atmosphere at this height is not sunlit, electrons become attached to form negative ions and the density of free electrons falls. PMWE is seen as a narrow layer descending from $70 \mathrm{~km}$ at dawn to $63 \mathrm{~km}$ at about 13:00 UT on 30 October. For ease of comparison, contour lines are superimposed on the uppermost colour plot to indicate the time/height regions where PMWE were detected by the EISCAT radar.

The lowermost panel of Fig. 1 shows the Doppler shift of the radar returns detected by the EISCAT VHF radar, again with superimposed contour lines to show when/where PMWE were detected. The Doppler shift has been calculated from the phase of the complex autocorrelation of the received signal at a lag of $2.7 \mathrm{~ms}$ (with $60 \mathrm{~s}$ integration), and is here expressed as the speed at which the scatterers are approaching (positive) or receding from the radar (negative). The maximum Doppler shift which can be resolved by this method without aliasing is $185 \mathrm{~Hz}$, corresponding to a speed of $124 \mathrm{~m} / \mathrm{s}$. This is well in excess of any expected scatterer travel speed in the direction of the radar beam, so we expect no aliasing. The observed scatterer travel speeds can be interpreted as the component of the neutral wind which is directed along the radar beam. Assuming that the wind is primarily horizontal, the beam-aligned component corresponds to half of the meridional wind speed (the beam is directed at an elevation of $60^{\circ}$ above horizontal).

\section{Discussion}

3.1 Large-scale morphology of PMWE layers and wind field

Enhanced mesospheric echoes were seen at about the same times and at similar heights with both the EISCAT VHF and ESRAD. The observations are made at locations which are about $220 \mathrm{~km}$ apart and correspond to different Bragg wavelengths, $0.67 \mathrm{~m}$ and $2.9 \mathrm{~m}$, respectively. The question arises as to whether the radars observed the same layers or not. We will discuss the similarities and differences between the layers based on their morphology.

The layers seen by the two radars are morphologically rather alike, occurring at approximately the same height ranges and lasting for similar amounts of time. A very distinct layer starts at $\sim 70 \mathrm{~km}$ altitude at dawn (06:00 UT) in both radars and descends to $\sim 63 \mathrm{~km}$, where it disappears at about 12:30 UT (Fig. 1). During this interval wave-like disturbances in height can be identified in the echoes from both radars. However, the layer seen by ESRAD is slightly $(0.5-1 \mathrm{~km})$ below that seen by EISCAT. The latter is also narrower in height than the former. A more exact comparison of the layer's appearance at dawn shows that the PMWE were detected by ESRAD starting at 05:55 UT, while the time of PMWE onset for the EISCAT is 06:25 UT. With ESRAD a new PMWE layer appears at about $68 \mathrm{~km}$ at 12:00 UT, and persists until $\sim 15: 00$ UT. There is a weak signature of similar PMWE at slightly higher altitude in EISCAT at the same time.

The atmospheric wind patterns shown in the lowermost panel in Fig. 1 show clear signatures of inertio-gravity waves with phases descending at about $0.6 \mathrm{~km} / \mathrm{h}$ (marked by the dashed lines below $65 \mathrm{~km}$ ). The layer of enhanced radar echo closely follows one of the wave minima, i.e. where the wind is receding from the radar, for most of the time. The main layer seen by ESRAD also descends at the same rate. Since we measure only one component of the wind field (the component along the radar beam), we cannot directly determine all of the wave parameters. However, some wave parameters can be directly estimated from Fig. 1: a vertical wavelength of about $4.5-5 \mathrm{~km}$, an apparent period of 7-9 $\mathrm{h}$ and an amplitude of the wave component of about $20 \mathrm{~ms}^{-1}$, which translates to an amplitude in meridional wind of $40 \mathrm{~ms}^{-1}$. In order to determine whether the wind shear associated with this wave might produce turbulence which could explain the PMWE, we need to consider how much greater the wave amplitude might be in some other direction. This is relatively straightforward for an inertio-gravity wave since the wind vector rotates with height, tracing an ellipse where the ratio of the major and minor axes depends on the intrinsic period of the wave. The intrinsic wave period will differ from the apparent period (which we can estimate directly from Fig. 1) due to the effect of background winds, through the relation $2 \pi / \mathrm{T}_{a p p}=\left(2 \pi / \mathrm{T}_{i n}\right)+\boldsymbol{k} \cdot \boldsymbol{U}$, where $\mathrm{T}_{a p p}$ and $\mathrm{T}_{i n}$ are the apparent and intrinsic periods, respectively, $\boldsymbol{k}$ is the wave vector and $\boldsymbol{U}$ is the (vector) background wind. For the discussion which follows, in particular to be able to estimate the maximum possible wind fluctuations associated with the wave in the direction perpendicular to our observations, it is important to consider whether the apparent period is likely to be less than or greater than the intrinsic period. To do this we must examine whether the wave is propagating in the direction of, or against the prevailing wind.

To estimate the direction of propagation of the inertiogravity wave, we make use of the perturbations in the phasedescent rate which can be seen between 65 and $75 \mathrm{~km}$ altitudes, most clearly between 06:00 and 10:00 UT. These are most likely due to changes in the background wind due to interference with other waves. One particularly large wave with a period of about $4 \mathrm{~h}$ can be seen at heights just above the PMWE layer. In Fig. 1, above $70 \mathrm{~km}$ altitude, the positions of wind maxima in this wave are shown. The 
meridional component is visible directly in the radar observations, as indicated by the dashed lines. The zonal component is inferred as lying one-quarter of a wavelength shifted from the meridional component (dotted lines). The directions of the zonal maxima are inferred on the basis that this is most likely to be an upward propagating wave, in which case the wind vector rotates clockwise with increasing height (e.g. Andrews et al., 1987). The phase-descent of the minimum in the inertio-gravity wave which is associated with the PMWE is fastest between 06:00 and 8:30 UT, and is close to zero or slightly upward between 8:30 and 10:00 UT. At the same time, the wind direction in the interfering wave rotates from eastward, through southward, to westward. The shortest apparent period (i.e. the fastest phase-descent speed) is associated with the eastward interfering wind, indicating that the inertio-gravity wave is propagating eastward. Since the background wind at the relevant heights in the mesosphere at this time of year is the eastward prevailing wind, this implies that $\boldsymbol{k} . \boldsymbol{U}$ is positive and the apparent period we observe at heights just below the PMWE layer, where the perturbations due to other waves seem to be small, is likely to be a lower limit to the intrinsic period.

A minimum horizontal wavelength of at least $450-500 \mathrm{~km}$ then follows from the relation $\omega^{2}=\left[\mathrm{f}^{2}+\mathrm{N}^{2}\left(\mathrm{k}^{2} / \mathrm{m}^{2}\right)\right]$, where $\omega$ is the wave angular frequency, $\mathrm{f}$ the Coriolis parameter, $\mathrm{N}^{2}$ the square of the buoyancy frequency (typically $3 \times 10^{-4} \mathrm{~s}^{-2}$ in the mesosphere), $\mathrm{k}$ and $\mathrm{m}$ the horizontal and vertical wave numbers, respectively (e.g. Andrews et al., 1987). As mentioned earlier, the horizontal wind vector in an inertio-gravity wave is expected to rotate with height, tracing an ellipse. According to wave polarisation relations, the ellipse axial ratio is $\left|\mathrm{v}^{\prime}\right| /\left|\mathrm{u}^{\prime}\right|=\mathrm{f} \omega^{-1}$, where $\left|\mathrm{u}^{\prime}\right|$ and $\left|\mathrm{v}^{\prime}\right|$ are the amplitudes of the wind perturbation components parallel and perpendicular to the direction of the wave group velocity. Theory requires that $\omega>\mathrm{f}$, so $\left|\mathrm{u}^{\prime}\right|>\left|\mathrm{v}^{\prime}\right|$ and the maximum wind is in the group propagation direction. The maximum windshears associated with the wave will then occur when the wind shear maximises in the direction of propagation - for an eastward propagating wave this would occur one-quarter of a wavelength shifted from the maximum wind shear seen in the direction of our observations $(\mathrm{N})$. So there is good reason to suspect that the PMWE layer in this case follows a maximum wind-shear in the zonal wind. However, we do not need to know the exact direction of propagation in order to find the maximum possible wind shear in the wave. The amplitude of the wave component in Fig. 1 (lowermost panel) is about $20 \mathrm{~ms}^{-1}$, which translates to an amplitude in meridional wind of $40 \mathrm{~ms}^{-1}$. This value must lie somewhere between $\left|u^{\prime}\right|$ and $\left|v^{\prime}\right|$, i.e. $\left|u^{\prime}\right| \geq 40 \mathrm{~ms}^{-1} \geq\left|v^{\prime}\right|$. Using the minimum wave period as discussed above, we find that $0.6<\left|\mathrm{v}^{\prime}\right| /\left|\mathrm{u}^{\prime}\right|<1$. So the maximum amplitude of the wind disturbance associated with the wave in any direction is $70 \mathrm{~m} \mathrm{~s}^{-1}$.

The main layer seen by ESRAD on 30 October follows a similar slow descent to the layer seen $220 \mathrm{~km}$ further north at EISCAT. It seems reasonable to assume that it follows the same phase location in the inertio-gravity wave, with the
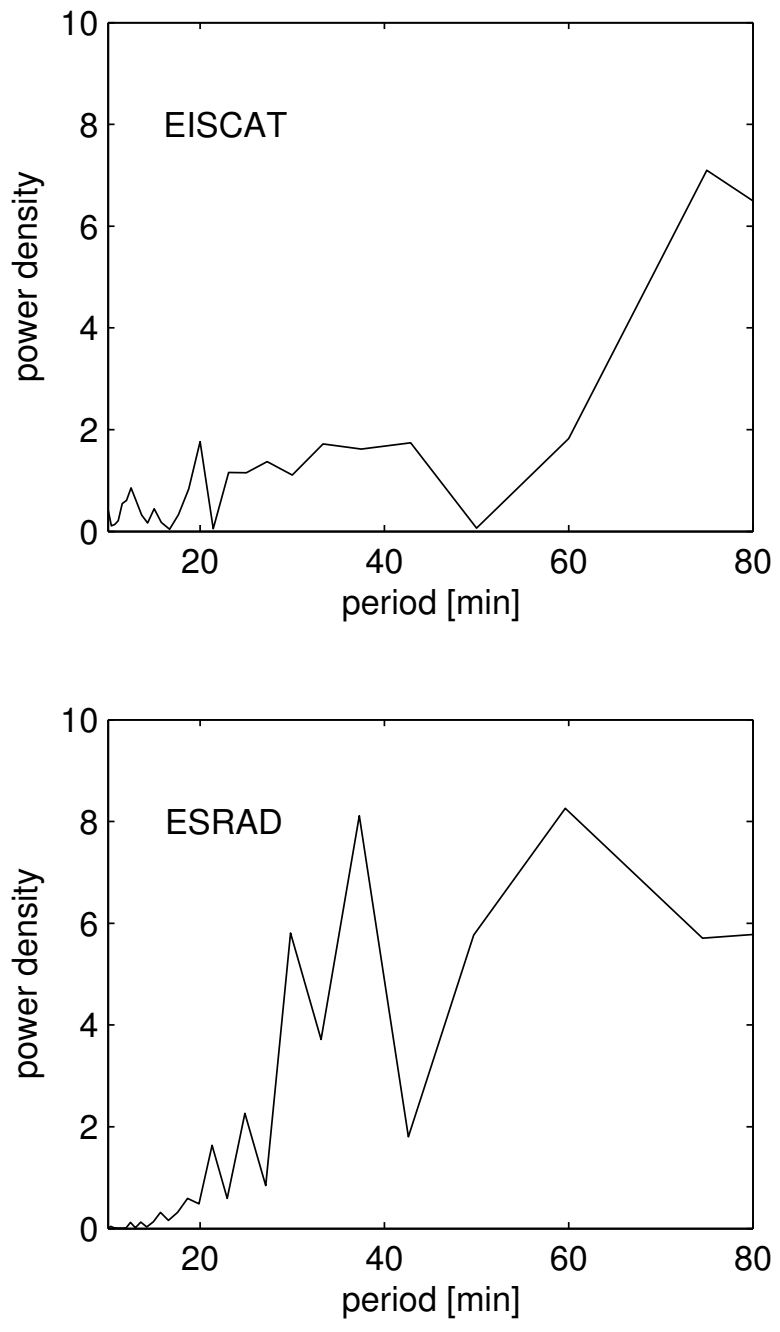

Fig. 2. Spectrum of the time variation of maximum signal strength in the PMWE layer between 06:30 and 11:30 UT (arbitrary units).

difference in heights at the two sites corresponding to an upward tilt of the phase front towards the north. The small height difference of 0.1-0.2 times the vertical wavelength of the wave indicates that propagation is not entirely eastward, but has at least a small northward component.

\subsection{Small-scale waves on 30 October}

The wave patterns seen by both radars have also been analysed in more detail. Power spectra of the times of maxima in signal intensity have been taken and compared to each other. The spectra have several peaks of about the same amplitude, meaning that they are caused by several interfering waves rather than a single wave. Spectral peaks are found at about $30 \mathrm{~min}, 40 \mathrm{~min}, 60 \mathrm{~min}-75 \mathrm{~min}$ for both radars, plus at 12 and $20 \mathrm{~min}$ for the EISCAT radar (Fig. 2). Such periods are typical for gravity waves observed in the mesosphere (such as those seen with ESRAD also during summer, Dalin et al., 2004). Thus, the radars probably have seen waves of the same origin. The lowest wave period observed $(12 \mathrm{~min})$ 
allows us to determine an upper limit for the buoyancy period, or equivalently a lower limit for the buoyancy frequency as $\mathrm{N}^{2}>7.6 \times 10^{-5} \mathrm{~s}^{-2}$.

By taking into account all similarities in morphology and the wave patterns in the layers seen by both radars we can conclude that they likely represent the same phenomenon. The horizontal extent on 30 October was then at least $220 \mathrm{~km}$ in the $\mathrm{N}-\mathrm{S}$ direction. The systematic differences in echo height between the radars can be explained as an association of the PMWE with an inertio-gravity wave travelling towards E-NE. The slight difference in onset time at dawn on 30 October may simply be spatial variability, but it might also be due to different sensitivities of radar echo power to the proportion of negative ions, at the different Bragg wavelengths.

\subsection{Origin of echoes: turbulent or not}

The likely spatial correlation between the main layer on 30 October and windshear in an inertio-gravity wave qualitatively suggests a role for turbulence. From our observations of the wind shear in the north-south direction, and the calculated maximum/minimum axial-ratio for the wind vector in the wave (see above), we find that the maximum wind shear associated with the inertio-gravity wave is $\mathrm{du} / \mathrm{dz}=5 \times 10^{-2} \mathrm{~s}^{-1}$. It is usually considered that turbulence will occur if the Richardson number, $\left.\mathrm{N}^{2} / \mathrm{du} / \mathrm{dz}\right)^{2}$, is less than 0.25 . This corresponds to $\mathrm{N}^{2}<2-6 \times 10^{-4} \mathrm{~s}^{-2}$. From the gravity wave spectrum we know only that $\mathrm{N}^{2}>7.6 \times 10^{-5} \mathrm{~s}^{-2}$, while typical values for the mesosphere are around $3 \times 10^{-4} \mathrm{~s}^{-2}$, so it seems that turbulence is likely. We can further estimate the turbulent energy dissipation rate $\varepsilon$ from $\varepsilon=\mathrm{K}_{m}(\mathrm{du} / \mathrm{dz})^{2}$, where $\mathrm{K}_{m}$ is the diffusion coefficient for turbulent momentum transfer (Lübken et al., 1993). The most direct information on $\mathrm{K}_{m}$ for the appropriate heights is from measurements using a large number of sounding rockets published by Lübken et al. (1993). A value close to $5 \mathrm{~m}^{2} \mathrm{~s}^{-1}$ was found to be representative, which gives a maximum energy dissipation rate of $12.5 \mathrm{~mW} / \mathrm{kg}$, corresponding to $\mathrm{du} / \mathrm{dz}=5 \times 10^{-2} \mathrm{~s}^{-1}$.

We calculate the theoretical radar reflectivity from neutral turbulence with this energy dissipation rate, assuming only molecular ions and electrons in the ionospheric plasma, using the method described in Stebel et al. (2004). Radar reflectivity is very sensitive to electron density, to vertical electron density gradient and to the ratio of negative-ions to electrons. In particular, the last of these quantities cannot be obtained directly from observations. In order to estimate this ratio we have used an ion-chemistry model for the lower ionosphere, together with calculations of ionospheric ionisation rate caused by solar proton fluxes (Kirkwood and Osepian, 1995). Proton fluxes have been obtained from the GOES satellites (http://www.ngdc.noaa.gov/stp/GOES/ goes.html). The results of the modelling for 30 October are compared with experimental electron densities derived from the EISCAT measurements in Fig. 3. EISCAT electron densities are from the backscatter power, as shown in Fig. 1, but with the PMWE removed by smooth interpolation between values above and below the PMWE. The calibration of the EISCAT data has also been checked by comparing $30-\mathrm{MHz}$ cosmic noise absorption calculated from the EISCAT electron density profiles with direct observations of absorption by the riometer at Abisko $\left(68.4^{\circ} \mathrm{N}, 18.8^{\circ} \mathrm{E}\right.$, http://www.sgo.fi/Data/Riometer/riometer.php). The calibration is found to be correct to within the $\sim 10 \%$ precision of this method.

Both in the EISCAT measurements and in the model results, one can clearly see a strong increase in electron density at dawn (around 06:00 UT) and a decrease at dusk (around 15:00 UT) due to detachment/attachment of electrons forming negative ions at night. High levels of incoming energetic protons ionize the atmosphere between $55 \mathrm{~km}$ and $85 \mathrm{~km}$ altitudes throughout the periods shown. The modelled densities show somewhat lower values below about $63 \mathrm{~km}$ than experimental electron densities. The reason for this might be imperfection in fitting of the high-energy tail of the proton spectra which are used for calculation of ionisation in the model. However, in general, the model electron densities show a very good agreement with the measured ones, particularly in the dawn/dusk transition periods, implying that the modelled negative ion densities must also be close to correct.

We used modelled negative ion densities, MSIS90E neutral densities and temperatures (Hedin, 1991), observed electron densities and an assumed turbulent energy dissipation rate of $12.5 \mathrm{~mW} / \mathrm{kg}$ for calculation of radar reflectivities expected from layers of neutral turbulence. This, and the method of calculation of observed volume reflectivity from ESRAD and EISCAT, are described in more detail in Stebel et al. (2004). In general, the "observed" reflectivities are likely to be underestimated (we assume filling of the scatter volume and, for ESRAD, no antenna losses), and theoretical turbulent values are the upper limits of those consistent with our wind-shear observations, and in practice among the highest of those observed in sounding-rocket campaigns (Lübken et al., 1993). The results of the calculations are presented in Fig. 4. The effect of negative ions on the expected radar scatter can be seen in the relatively low values of the theoretical curves at 05:55 UT and 06:25 UT, compared to later in the day. The observations also show increasing echo strengths between these dawn examples, however later observed radar echo strengths for both radars are consistently 2-3 orders of magnitude higher than the theoretical predictions. Turbulent energy dissipation rates of about $1 \mathrm{~W} / \mathrm{kg}$ would be needed to obtain the observed strength of echoes of both radars, which seems unrealistic in relation to the observed wind shear. It might be argued that interference from small-scale gravity waves could increase the wind shear at times. However, the long persistence of the PMWE with strong echoes present without a break, throughout perturbations of the layer by several gravity waves, suggests that this explanation is not sufficient and that the energy for producing any turbulence must come from the main inertio-gravity wave. If the value of $\mathrm{K}_{m}$ reported by Lübken et al. (1993) is truly representative, the wind shear would have to be increased by a factor of 9 to cause turbulent energy dissipation of $1 \mathrm{~W} / \mathrm{kg}$, implying 


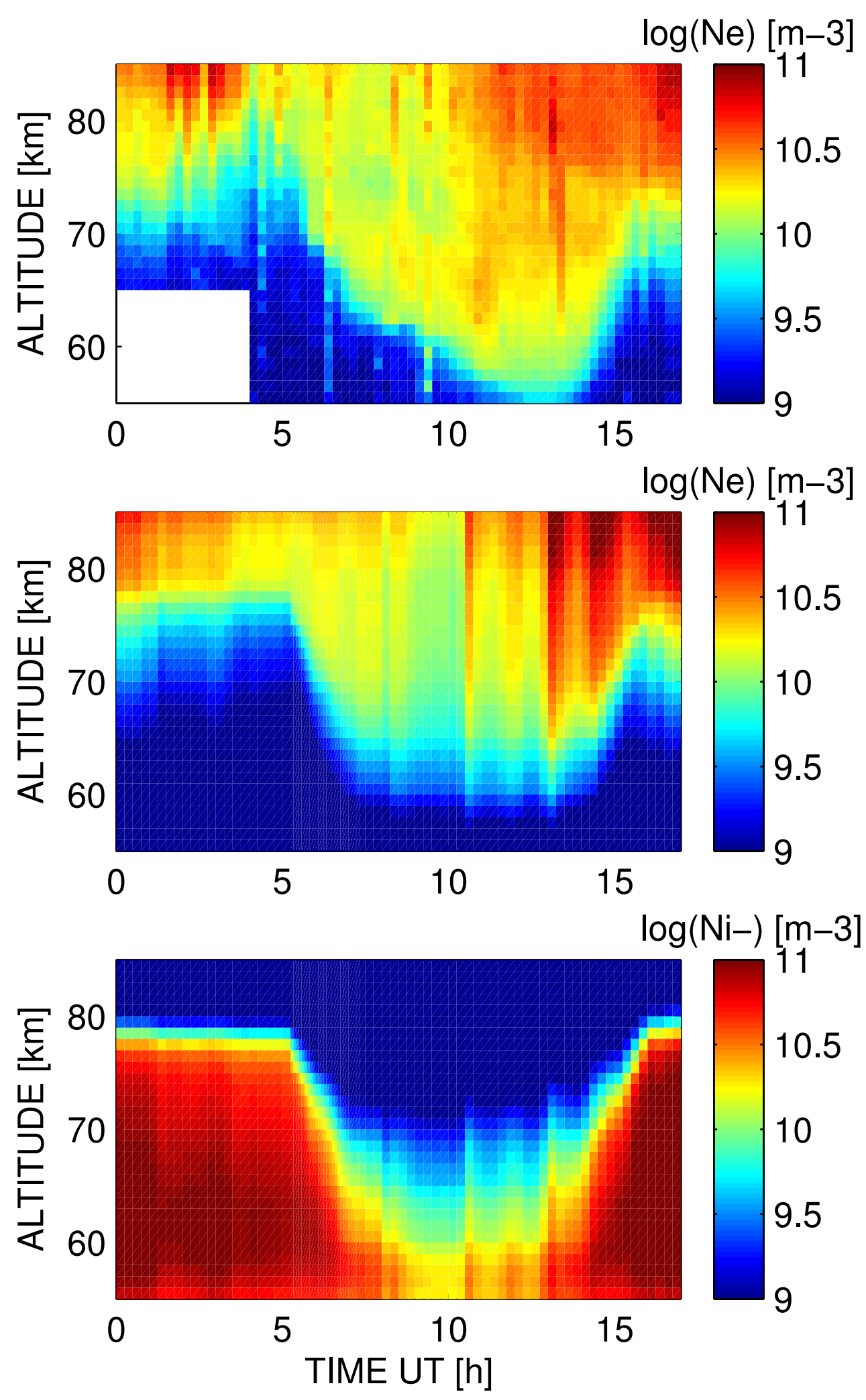

Fig. 3. Comparison of observations with model results: Electron density measured by the EISCAT VHF radar (the upper panel), modelled electron density (middle panel) and modelled negative ion density (bottom panel). 

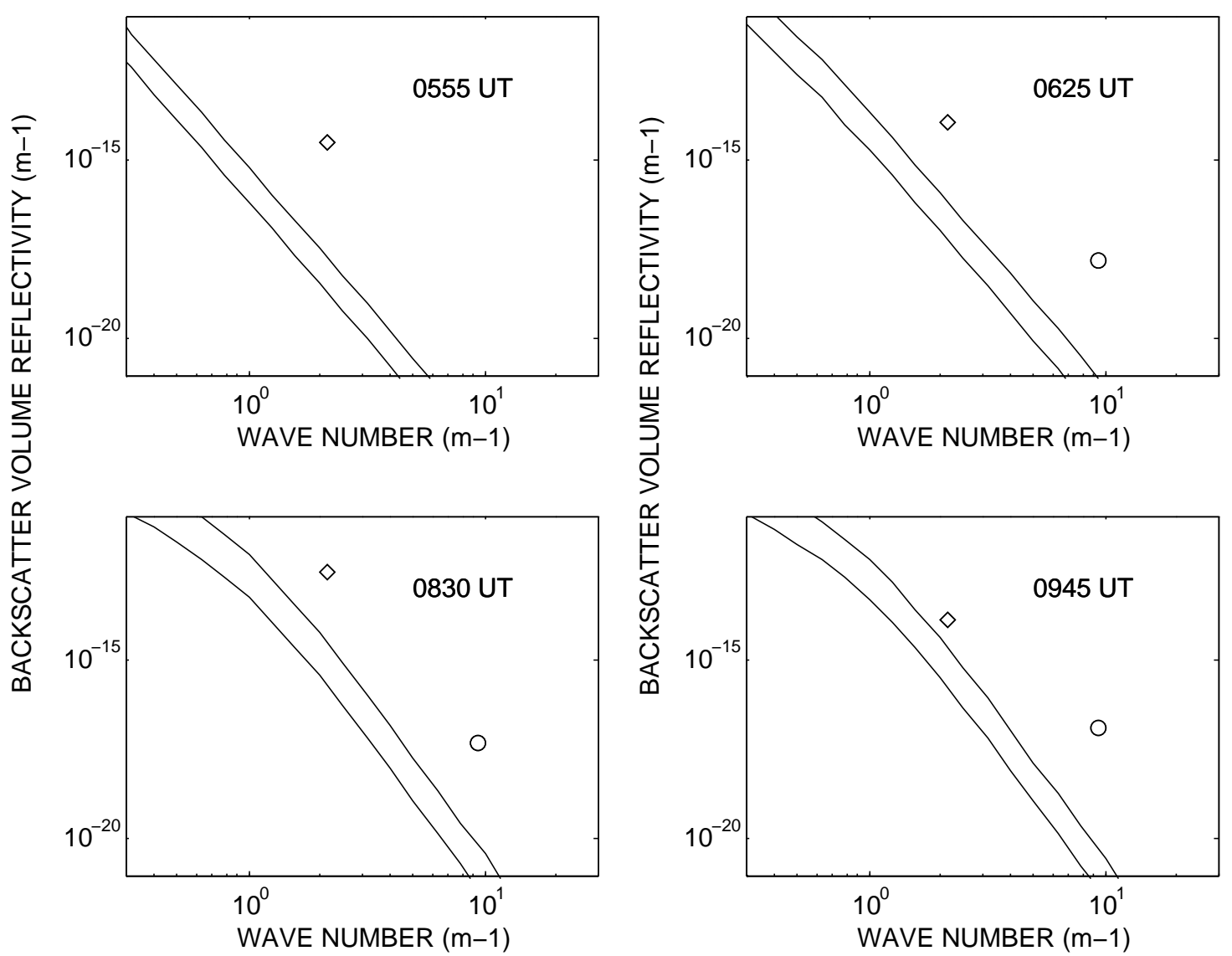

Fig. 4. Radar volume reflectivities estimated from radar observations (ESRAD as diamonds, EISCAT as circles) and from turbulent theory (lines) for four different times indicated on the plots. The lower line on each plot correspond to $\mathrm{N}^{2}=6 \times 10^{-4} \mathrm{~s}^{-2}$, the upper line to $\mathrm{N}^{2}=7.6 \times 10^{-5} \mathrm{~s}^{-2}$. All curves for energy dissipation rate of $12.5 \mathrm{~mW} / \mathrm{kg}$. Neutral densities and temperatures are from the MSIS $90 \mathrm{E}$ model (Hedin, 1991), electron and ion densities and electron density gradient from the model in Fig. 3, Schmidt number is calculated from the ion densities (including negative ions). Prandtl number is assumed to be 0.83 (see text and Stebel et al., 2004 for further details).

physically impossible wind amplitudes in the wave, in excess of the speed of sound.

The discrepancy between turbulence theory and observations for PMWE seems to be very similar to that which arose in interpreting PMSE, before charged aerosol particles were introduced (see, e.g. Cho et al., 1992). Kirkwood et al. (2002a) suggested that layers of dust particles may be present in the case of PMWE, as has been proposed for PMSE. Comparison of earlier ESRAD layers with results from other instruments, such as lidar and sounding rockets, gave additional arguments in favour of dust/smoke particles (Kirkwood et al., 2002b; Stebel et al., 2004). In the case reported here, the presence of charged aerosols could act to extend the spectrum of turbulent fluctuations due to a reasonable level of turbulence so that shorter scale-sizes would be maintained longer in the plasma. The presence of charged aerosol particles would also allow plasma-fluctuations to persist continuously while neutral turbulence is more likely to be intermittent (Rapp et al., 2003). However, the origin of such particles at $50-70 \mathrm{~km}$ altitude under winter conditions is still open to speculation - the relatively high temperatures and low concentration of water vapour would not allow iceparticles to form. Dust/smoke from meteoroid ablation are expected to be present (Hunten, 1981), and the concentration and size at PMWE heights are predicted to be a few times $10^{9} \mathrm{~m}^{-3}$ and a few $\mathrm{nm}$, respectively. According to Rapp and Lübken (2001), aerosol particles of this size can be expected to each capture a single electron. Since the background electron density is about an order of magnitude larger than the expected aerosol-particle density, and the size of most of the aerosol particles is expected to be only a few $\mathrm{nm}$, any electron density irregularities would be expected to disperse rapidly (Rapp and Lübken, 2004).

\section{Conclusions}

We have observed PMWE simultaneously with the EISCAT VHF and ESRAD radars. After considering the morphology of the layers and their relation to observed atmospheric waves, we conclude that the radars have likely seen the same phenomenon and that the most long-lasting layer is likely associated with wind shear in an inertio-gravity wave. We have 
employed an ion-chemistry model to calculate parameters necessary to relate wind-shear induced turbulence to radar backscatter. The accuracy of the model has been verified by comparison with electron densities measured by the EISCAT radar. We find that observed radar signal strengths are 2-3 order of magnitude stronger than the maximum which can be expected from neutral turbulence alone, even when we use the highest estimate of the level of turbulence, and the lowest estimate of the buoyancy frequency, which are consistent with the wind-shear and gravity wave observations. One possible explanation for this discrepancy is that previously published results relating wind shear to turbulence and turbulence to radar signal scatter are substantially in error. A second possibility is that some additional or alternative mechanism may be involved in producing PMWE, such as layers of charged dust/smoke particles.

Acknowledgements. EISCAT is an international association supported by the research councils of Finland (SA), France (CNRS), the Federal Republic of Germany (MPG), Japan (NIPR), Norway (NFR), Sweden (VR) and the United Kingdom (PPARC). ESRAD is a joint venture between Swedish Institute of Space Physics and Swedish Space Corporation, Esrange. JE is funded by the Swedish Graduate School for Space Technology.

Topical Editor M. Lester thanks two referees for their help in evaluating this paper.

\section{References}

Andrews, D. G., Holton, J. R., and Leovy, C. B.: Middle Atmosphere Dynamics, Academic Press Inc., London, England, 1987.

Balsley, B. B., Ecklund, W. L., and Fritts, D. C.: VHF echoes from the high-latitude mesosphere and lower thermosphere: observations and interpretations, J. Atmos. Sci., 40, 2451-2466, 1983.

Barabash, V., Kirkwood, S., Feofilov, A., and Kutepov, A.: Polar Mesosphere Summer Echoes during July 2000 Solar Proton Event, Ann. Geophys., 22, 759-771, 2004,

SRef-ID: 1432-0576/ag/2004-22-759.

Chilson, P., Kirkwood, S., and Nilsson, A.: The Esrange MST radar: a brief introduction and procedure for range validation using balloons, Radio Sci. 34, 427-436, 1999.

Cho, J. Y. N. and Röttger, J.: An updated review of polar mesosphere summer echoes: Observation, theory and their relationship to noctilucent clouds and subvisible aerosols, J. Geophys. Res., 102, 2001-2020, 1997.

Cho, J. Y. N., Hall, T. M., and Kelley, M. C.: On the role of charged aerosols in polar mesosphere summer echoes, J. Geophys. Res., 97, 875-886, 1992.

Collis, P. N., Rietveld, M. T., Röttger, J., and Hocking, W. K.: Turbulence scattering layers in the middle-mesosphere observed by the EISCAT 224-MHz radar, Radio Sci., 27, 97-107, 1992.

Czechowsky, P., Reid, I., Rüster, I. M., and Schmidt, G.: VHF radar echoes observed in the summer and winter polar mesosphere over Andøya, Norway, J. Geophys. Res., 94, 5199-5217, 1989.

Dalin, P., Kirkwood, S., Moström, A., Stebel, K., Hoffmann, P., and Singer, W.: Observation of gravity waves in noctilucent clouds, Ann. Geophys., 22, 1875-1884, 2004.
Havnes O., Brattli, A., Aslaksen, T., Singer, W., Latteck, R., Blix, T., Thrane, E., and Troim, J.: First common volume observations of layered plasma structures and PMSE by rocket and radar, Geophys. Res. Lett., 28, 1419-1422, 2001.

Hedin, A. E.: Extension of the MSIS thermosphere model into the middle and lower atmosphere, J. Geophys. Res., 96, 1159-1172, 1991.

Hervig, M., Thompson, R. E., McHugh, M., Gordley, L. L., Russell III, J. M., and Summers, M. E.: First confirmation that water ice is the primary component of polar mesospheric clouds, Geophys. Res. Lett., 28, 971-974, 2001.

Hill, R. J.: Nonneutral and quasi-neutral diffusion of weakly ionized multiconstituent plasma, J. Geophys. Res., 83, 989-998, 1978.

Hunten, D. M., Turco, R. P., and Toon, O. B.: Smoke and dust particles of meteoric origin in the mesosphere and thermosphere, J. Atmos. Sci., 37, 1342-1357, 1981.

Kirkwood, S. and Osepian, A.: Quantitative studies of energetic particle precipitation using incoherent scatter radar, J. Geomag. Geolectr., 47, 783-799, 1995.

Kirkwood, S. , Barabash, V., Belova, E., Nilsson,H., Rao, T. N., Stebel, K., Osepian, and A., Chilson, P. B.: Polar Mesosphere Winter Echoes during Solar Proton Events, Advances in Polar Upper Atmosphere Research, 16, 111-125, 2002a.

Kirkwood, S., Barabash, V., Belova, E., Nilsson, H., Rao, T. N., Stebel, K., Blum, U., Fricke, K.-H., Osepian, A., and Chilson, P. B.: Polar Mesosphere Winter Echoes by ESRAD, EISCAT and lidar, memoirs of the British Astronomical Association, vol. 45, paper 07, September, 2002b.

Kirkwood, S., Belova, E., Dalin, D., Fricke, K.-H., Blum, U., Schmidlin, F., and Goldberg, R. A. : Polar mesosphere winter echoes during MaCWAVE Proceedings of the ESA/PAC meeting in St. Gallen, ESA-SP-530, 357-362, 2003.

Lie-Svendsen, O., Blix, T. A., Hoppe, U.-P., and Thrane, E. V.: Modeling the plasma response to small-scale aerosol particle perturbations in the mesopause region, 108, D8, doi:10.1029/2002JD002753, 2003.

Lübken, F.-J., Hillert, W., Lehmacher, G., and von Zahn, U.: Experiments revealing small impact of turbulence on the energy budget of the mesosphere and lower thermosphere, J. Geophys. Res. 98, 20369-20384, 1993.

Lübken, F.-J.: Seasonal variation of turbulent energy dissipation rates at high latitudes as determined by in situ measurements of neutral density fluctuations, J. Geophys. Res., 102, $13441-$ $13456,1997$.

Rapp, M. and Lübken, F.-J.: Modelling of particle charging in the polar summer mesosphere: Part 1 - General results, J. Atmos. Sol. Terr. Phys. 63, 759-770, 2001.

Rapp, M., Lübken, F.-J., Hoffman, P., Latteck, R., and Baumgarten, G.: PMSE dependence on aerosol charge number density and aerosol size, J. Geophys. Res. 108, 8441, doi:10.1029/2002JD002650, 2003.

Rapp, M. and Lübken, F.-J.: Polar mesosphere summer echoes (PMSE): Review of observations and current understanding, Atmos. Chem. Phys., 4, 2601-2633, 2004,

SRef-ID: 1680-7324/acp/2004-4-2601.

Stebel, K., Blum, U., Fricke, K.-H., Kirkwood, S., Mitchell, N., and Osepian, A.: Joint radar/lidar observations of possible aerosol layers in the winter mesosphere, J. Atmos. Sol. Terr. Phys., 66(11), 957-970, 2004. 